\title{
A prospective study of age trends of high-risk human papillomavirus infection in rural China
}

\author{
Le-Ni Kang ${ }^{1}$, Philip E Castle ${ }^{2}$, Fang-Hui Zhao ${ }^{1}$, Jose Jeronimo ${ }^{3}$, Feng Chen ${ }^{1}$, Pooja Bansil', Jing Li ${ }^{1}$, Wen Chen', \\ Xun Zhang ${ }^{1}$ and You-Lin Qiao ${ }^{1 *}$
}

\begin{abstract}
Background: In China, high-risk human papillomavirus (HR-HPV) prevalence is unexpectedly high in older women, but the possible reasons have not been well studied yet. This study investigated the age trends of HR-HPV infection in a prospective study.

Methods: A total of 7397 women aged 25-65 years without cervical precancer or cancer were evaluated during 2010-2011 with a stratified sample of 2791 women re-evaluated after one year. Test results for careHPV and careHPV16/18/45 were used to describe the HR-HPV prevalence, incidence and clearance. Risk factors associated with HR-HPV infections were explored using a logistic regression model.

Results: The overall HR-HPV prevalence was $13.1 \%$ at baseline, with a peak of $19.3 \%$ in women aged 55-59 years. The prevalence of HR-HPV ( $p$ for trends < 0.001), HPV16/18/45 ( $p$ for trends $=0.002$ ), and HR-HPV other than HPV16/ $18 / 45$ ( $p$ for trends $=0.002$ ) generally increased with increasing age. Number of infections that cleared was generally greater than number of incident infections within age groups. One-year clearance rate decreased with increasing age ( $p$ for trends $<0.001$ ), however, incidence rate was unrelated to age ( $p$ for trends $=0.159$ ). Risk factors that associated with HR-HPV infection differed between younger and older women.
\end{abstract}

Conclusions: The greater HR-HPV prevalence in older versus younger women in rural China may be explained by a cohort effect, higher than expected incidence, and/or poorer clearance at older age.

Keywords: Human papillomavirus, Infection, Age, Risk factor, Cohort effect

\section{Background}

Previous studies of age-specific high-risk human papillomavirus (HR-HPV) prevalence have demonstrated substantial variability across geographical regions [1-3]. Typically, women within a few years of their age of sexual debut were observed to have the highest HR-HPV prevalence. A second peak of HR-HPV prevalence around the age of menopause has been observed in some populations $[4,5]$, while absent in others $[6,7]$.

Due to the lack of well-organized, nation-wide HPVbased cervical cancer screening programmes, the age distribution of HPV prevalence in China has not been well demonstrated, and results from population-based studies also differed from each other [8-12]. More recently, a

\footnotetext{
* Correspondence: qiaoy@cicams.ac.cn

${ }^{1}$ Cancer Institute and Hospital, Chinese Academy of Medical Sciences and Peking Union Medical College, 17 Panjiayuan Lane, Beijing 100021, China Full list of author information is available at the end of the article
}

pooled analysis reported a pronounced increase of HRHPV prevalence in women around the age of menopause in rural China [13]. However, almost all mentioned studies were cross-sectional in nature (i.e., no longitudinal followup), limiting the interpretation of age-specific HR-HPV prevalence in China.

In particular, persistent infection with HR-HPV is the necessary cause of cervical cancer and its precancerous lesions such as cervical intraepithelial neoplasia grade 2 or 3 (CIN2/3) [14-16]. One-year HR-HPV persistence strongly predicts which infection will continue to persist [17] and progress to CIN2/3 [18]. In the U.S., evidence of one-year HR-HPV persistence results in referral to colposcopy [19]. World Health Organization (WHO) is now considering 6month persistent infection as a surrogate endpoint for $\mathrm{HPV}$ vaccine trials.

We therefore wanted to further characterize the agespecific patterns of HR-HPV infections in rural China. 
Using data from a multi-center study of lower-cost molecular HPV tests in rural China, we described the prevalence and short-term (one-year) dynamics of HR-HPV infection as measured by careHPV (Qiagen, Gaithersburg, MD, USA), a DNA test for a pool of 13 carcinogenic HPV genotypes and one possible carcinogenic HPV genotype, which had been evaluated in multiple countries [20,21], and a research-use only DNA test for a pool of HPV16,18, and 45 (HPV16/18/45) made available for the careHPV platform (“careHPV16/18/45"). We also investigated risk factors for prevalence, incidence, and one-year clearance of HR-HPV.

\section{Methods}

\section{Study population and procedures}

A total of 7541 women aged 25- to 65-year living in rural villages in Shanxi, Henan and Jiangxi provinces were enrolled from October 2010 to August 2011 in a study called "Screening Technologies to Advance Rapid Testing for Cervical Cancer Prevention-Utility and Program Planning (START-UP)" Project. Participant recruitment processes and study procedures were described elsewhere [22]. Briefly, women were considered to be eligible if they: 1) had not been previously diagnosed with cervical cancer; 2) had a cervix; 3) were not pregnant; 4) were physically able to undergo routine cervical cancer screening; and 5) were able to provide informed consent. Each participant provided a written informed consent and a staff-administered questionnaire survey was conducted in a private room. Six screening tests were performed on each participant, including OncoE6 $6^{\text {ma }}$ (Arbor Vita Corporation, Fremont, CA, USA), careHPV and Hybrid Capture 2 (HC2) (QIAGEN, Gaithersburg, MD, USA) tested on both self- and clinician-collected specimens and visual inspection with acetic acid (VIA). Woman who were tested positive by any of the six tests or tested negative by all six tests but was selected as a part of $\sim 10 \%$ random sample underwent a rigorous colposcopic evaluation using a biopsy protocol as previously described [23]. The primary histological diagnoses were done by two pathologists in CICAMS until reaching an agreement. A U.S. pathologist independently reviewed each initial biopsy or surgical specimen diagnosed as $\mathrm{CIN} 2+$, and any discordant diagnoses were settled from discussions with the Chinese pathologists [22].

One hundred and forty four women with histology confirmed CIN2+ at baseline were excluded with 7397 women in this analysis. Of the 2147 screen-positive women, 1859 (86.6\%) returned for one-year follow-up; of the 5250 screen-negative women, 1014 were randomly selected for one-year follow-up, of whom, 932 (91.9\%) returned in a year (Figure 1). All follow-up procedures

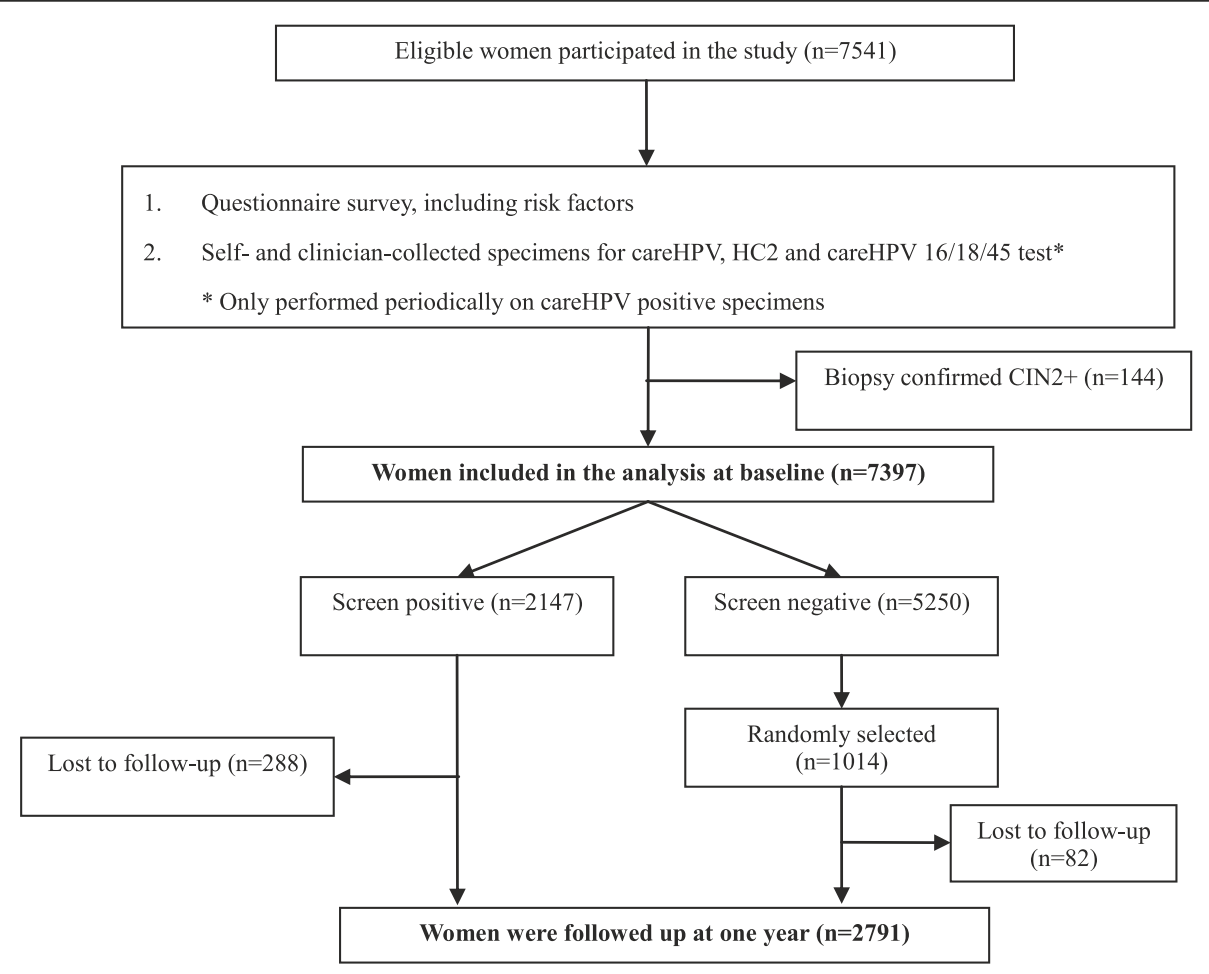

Figure 1 Flowchart of inclusion and exclusion of the study participants. At baseline, 144 women were excluded because of biopsy confirmed CIN2+, with 7397 women in the baseline analysis. 288 of the 2147 baseline screen positives were lost to follow-up and 82 of the 1014 randomly selected baseline screen negatives were lost to follow-up, which added up to 2791 women in the follow-up analysis. CIN2+:cervical intraepithelial neoplasia grade 2 or above. 
were the same as the baseline screening without any questionnaire survey.

This study is part of the START-UP Project which was approved by the PATH and Cancer Institute and Hospital, Chinese Academy of Medical Sciences (CICAMS) institutional review boards (IRBs).

\section{HPV DNA testing}

careHPV was used to detect HPV DNA in both selfand clinician-collected specimens. care HPV is a $\mathrm{CE}$ Marked and Chinese Food and Drug (CFDA)-approved signal-amplification DNA assay that uses antibody capture of HPV DNA and RNA probe hybrids with chemiluminescent signal detection. Same as HC2 [24], the relative light unit/cutoff ratio (RLU/CO) is provided as a semi-quantitative measurement of HPV viral load. All careHPV-positive specimens were also tested periodically in a batch-wise fashion for HPV16, 18, and 45 by careHPV16/18/45.

\section{Statistical analysis}

The prevalence of overall HR-HPV and HPV16/18/45 were demonstrated directly by careHPV and careHPV16/ 18/45 results, while the prevalence of HR-HPV other than HPV16/18/45 (other HR-HPV) was inferred as careHPVpositive but careHPV16/18/45-negative.

The overall HR-HPV prevalence at baseline was standardized by using the world standard population that was reported by the WHO in 2001 [25]. Age-specific prevalence of overall HR-HPV, HPV16/18/45 and other HRHPV at baseline were simply presented by numbers and rates. Cochran-Armitage trend test was used to test the age trends. Univariate and multivariate logistic regression models were used to calculate the crude and adjusted odds ratios (ORs) of risk factors with 95\% confidence intervals (CIs) presented by Wald $\varkappa^{2}$ statistics. The HPV status in the successive visits were used to demonstrate incidence $(-/+)$ and clearance $(+/-)$. The number of incidence was adjusted for approximately $20 \%$ sampling fraction of baseline screen-negative women. McNemar's $x^{2}$ test was used to compare the estimated number of incidence and clearance. The adjusted prevalence at follow-up was determined by the estimated number of incidence and clearance.

The results were confirmed by using $\mathrm{HC} 2$ outcomes (data not shown). To increase the analytic sensitivity, these analyses were redone by combining the careHPV and HC2 results (i.e., HPV positive was defined by either careHPV positive or $\mathrm{HC} 2$ positive).

SPSS 17.0 (SPSS Inc., Chicago, USA) was used to analyze the data. Statistical significance was assessed by two-tailed tests with an $\alpha$ level of 0.05 .

\section{Results}

The median, mean, and age range of the participants were $44,44.5$, and $25-65$ years, respectively; $27.5 \%$ of the participants were menopausal at baseline, and the mean age at menopause was 48.7 years. Most women were Han ethnicity $(99.9 \%)$, farmers $(75.5 \%)$, currently married (97.1\%), and of less than 12 years' education (98.2\%). Most women reported that they did not smoke (99.6\%) or drink alcohol (91.5\%). Most women have self-reported only one sexual partner in their lifetime (87.3\%).

Overall, 969 of 7397 women (13.1\%, 95\% CI: 12.3\%13.9\%) were HR-HPV positive at baseline, and the positive rates varied among study sites (12.8\% for Yangcheng, $11.9 \%$ for Xinmi, and $15.4 \%$ for Tonggu). The prevalence of HR-HPV age-standardized to the world's standard population was $14.2 \%$ (95\% CI: $13.4 \%-15.0 \%$ ). The crude prevalence of HPV16/18/45 was $2.9 \%$ (22.3\% of all HRHPV) and of other HR-HPV was $10.2 \%$.

Risk factors associated with the HR-HPV infection are described in Table 1. Univariate analysis showed that age, household income, marital status, age at first menstruation period, age at first sexual intercourse, number of lifetime sex partners, number of sex partners in the past 6 months, age at first pregnancy, number of live births, and menopausal status were significantly associated with HR-HPV infection. In the multivariate model that was adjusted for study sites, education levels and oral contraceptive history, women who were not currently married ( $\mathrm{OR}=1.50,95 \% \mathrm{CI}: 1.07-2.12)$, younger at sex initiation ( $\leq 19$ vs. $\geq 23, \mathrm{OR}=1.23,95 \% \mathrm{CI}$ : 1.00-1.51), had more than one lifetime sex partners $(\mathrm{OR}=1.30,95 \% \mathrm{CI}: 1.07-1.58)$, and postmenopause $(\mathrm{OR}=1.47,95 \% \mathrm{CI}: 1.26-1.71)$ were significantly more likely to have HR-HPV infections. Number of sex partners in the past 6 months was not found to be the independent risk factor for HR-HPV infections (Multivariate analysis: $\mathrm{p}=0.086$ ).

Risk factors associated with HR-HPV infections have also been stratified by tertiles of age (i.e., 25-40, 41-48 and 49-65 years), with the prevalence of $11.4 \%, 12.4 \%$, and $15.8 \%$, respectively (Table 2 ). Household income, marital status, age at first menstruation period and age at first pregnancy were found to be associated with HR-HPV infection in women aged 25-40 years. By comparison, age at first intercourse showed significant association in 41 to 48-year-old women; and lifetime number of sex partners and menopausal status were significantly associated with having HR-HPV in women aged 49-65 years.

Figure 2 illustrates the age-specific prevalence of overall HR-HPV, HPV16/18/45 and other HR-HPV at baseline by 5 -year intervals. The age-specific prevalence of overall HRHPV between 25 and 54 years formed a "U-shaped curve", with a prevalence of $13.2 \%$ in women aged $25-29$ years and $13.9 \%$ in women aged $50-54$ years and a nadir of $10.9 \%$ in women aged 30-34 years. The prevalence peaked in the 
Table 1 Risk factors associated with overall HPV infection at baseline

\begin{tabular}{|c|c|c|}
\hline Variables & $\mathrm{N}(\%)$ & $\begin{array}{l}\text { HPV } \\
\text { positive, }\end{array}$ \\
\hline \multicolumn{3}{|l|}{ Age } \\
\hline $25-29$ & $326(4.4)$ & $43(13.2)$ \\
\hline $30-34$ & $631(8.5)$ & $69(10.9)$ \\
\hline $35-39$ & $1330(18.0)$ & $153(11.5)$ \\
\hline $40-44$ & $1555(21.0)$ & $188(12.1)$ \\
\hline $45-49$ & $1425(19.3)$ & $172(12.1)$ \\
\hline $50-54$ & $906(12.2)$ & $126(13.9)$ \\
\hline $55-59$ & $846(11.4)$ & $163(19.3)$ \\
\hline $60-65$ & $378(5.1)$ & $55(14.6)$ \\
\hline \multicolumn{3}{|c|}{ Household income (Yuan) $)^{\S}$} \\
\hline$\leq 3000$ & $2609(35.4)$ & $373(14.3)$ \\
\hline $3001-5000$ & $2254(30.6)$ & $268(11.9)$ \\
\hline$\geq 5001$ & $2502(34.0)$ & $323(12.9)$ \\
\hline \multicolumn{3}{|c|}{ Marital status } \\
\hline Married & $7180(97.1)$ & $920(12.8)$ \\
\hline Others & $217(2.9)$ & $49(22.6)$ \\
\hline \multicolumn{3}{|c|}{ Age at first menstruation period (years) ${ }^{\S}$} \\
\hline$\leq 14$ & $2654(35.9)$ & $323(12.2)$ \\
\hline $15-16$ & $2686(36.4)$ & $336(12.5)$ \\
\hline$\geq 17$ & $2047(27.7)$ & $309(15.1)$ \\
\hline
\end{tabular}

Age at first sexual intercourse (years) ${ }^{\S}$

$\begin{array}{lll}\leq 19 & 1499(20.3) & 252(16.8) \\ 20-22 & 4022(54.4) & 487(12.1) \\ \geq 23 & 1874(25.3) & 230(12.3)\end{array}$

No. of lifetime sex partners $\$$

$1 \quad 6460(87.3) \quad 815(12.6)$

$\geq 2 \quad 936(12.7) \quad 154(16.5)$

No. of sex partners in the past 6 months

\begin{tabular}{lcll}
0 & $763(10.3)$ & $121(15.9)$ & 1.0 \\
1 & $6553(88.6)$ & $831(12.7)$ & $\mathbf{0 . 7 7}(0.63-0.95)$ \\
$\geq 2$ & $81(1.1)$ & $17(21.0)$ & $1.41(0.79-2.50)$ \\
\multicolumn{2}{l}{ Age at first pregnancy (years) } & & $\boldsymbol{p}=\mathbf{0 . 0 0 1}$ \\
$\leq 20$ & $1954(26.6)$ & $302(15.5)$ & 1.0 \\
$21-23$ & $3553(48.4)$ & $427(12.0)$ & $\mathbf{0 . 7 5}(0.64-0.88)$ \\
$\geq 24$ & $1834(25.0)$ & $227(12.4)$ & $\mathbf{0 . 7 7}(0.64-0.93)$ \\
No. of live births & & & $\boldsymbol{p}<\mathbf{0 . 0 0 1}$ \\
$0-2$ & $5438(73.5)$ & $661(12.2)$ & 1.0 \\
$\geq 3$ & $1958(26.5)$ & $307(15.7)$ & $\mathbf{1 . 3 4}(1.16-1.56)$
\end{tabular}

$0.91(0.64-1.29)$

$0.90(0.63-1.29)$

$1.06(0.73-1.54)$

1.57 (1.09-2.26)

$1.12(0.73-1.72)$

$p=0.044$

1.0

$\mathbf{0 . 8 1}(0.68-0.96)$

0.89 (0.76-1.04)

$p<0.001^{*}$

1.0

$1.99(1.43-2.75)$

$p=0.007$

1.0

$1.03(0.88-1.22)$

$1.28(1.09-1.52)$

$p<0.001^{*}$

1.0

$\mathbf{0 . 6 8}(0.58-0.80)$

$\mathbf{0 . 6 9}(0.57-0.84)$

1.0

1.36 (1.13-1.65)

$p=0.006$

1.0
Table 1 Risk factors associated with overall HPV infection at baseline (Continued)

\begin{tabular}{llll}
\hline \multicolumn{2}{l}{ Menopausal status } & & $\boldsymbol{p}<\mathbf{0 . 0 0 1 *}$ \\
No & $5363(72.5)$ & $629(11.7)$ & 1.0 \\
Yes & $2033(27.5)$ & $339(16.7)$ & $\mathbf{1 . 5 1}(1.31-1.74)$
\end{tabular}

NOTE: *Risk factors of statistical significance in multivariate analysis which was adjusted for study sites, education levels and oral contraceptive history.

${ }^{\S}$ Missing values were excluded in the analysis. Bold type indicates statistical significance $(p<0.05)$. HPV = human papillomavirus; $\mathrm{OR}=$ odds ratio; $\mathrm{Cl}=$ confidence interval.

$p=0.001^{*}$

55-59 year age group at $19.2 \%$ and then decreased to $14.6 \%$ in the $60-65$ year age group. A similar age pattern was observed for other HR-HPV. In contrast, the prevalence of HPV16/18/45 appeared to rise steadily with age $\mathrm{p}$ for trend $=0.002$ ) but there was no spike in the prevalence in the 55-59 year age group. The HR-HPV prevalence performed on the definition of either careHPV positive or $\mathrm{HC} 2$ positive showed similar age trends.

The average follow-up time of the stratified sample of women was $11.7(\mathrm{SD}=0.3)$ months. The crude and sampling fraction-adjusted HR-HPV prevalence at follow-up was $20.6 \%$ and $11.1 \%$, respectively. The net change in HR-HPV infection is demonstrated in Table 3. The total and age-specific numbers of new HPV infection were less than those of HPV clearance, except for women aged 3539 and 60-65 years, although most of the differences were not statistically significant.

The age trends of incidence and clearance of overall HRHPV, HPV16/18/45 and other HR-HPV are illustrated in Figure 3. The clearance of overall HPV, HPV16/18/45 and other HPV declined with increasing age ( $\mathrm{p}$ for trends $<0.05$, for all), while no significant trends for incidence of overall HR-HPV, HPV16/18/45 and other HR-HPV were observed ( $p$ for trends $>0.05$, for all). The HR-HPV incidence and clearance rates performed on the definition of either care HPV positive or $\mathrm{HC} 2$ positive showed similar results.

The baseline risk factors of HR-HPV incidence and clearance are also investigated (Table 4). Women who had more than one sex partners in the last 6 months were more likely to have an incident HR-HPV infection at the one-year follow-up ( 2 vs. $0, \mathrm{OR}=7.80,95 \%$ CI: 2.46 24.75), while older women and women with higher baseline HR-HPV signal strength, a semi-quantitative measure of HR-HPV viral load [26,27], were less likely to clear the infection. Infection of HPV16/18/45 was marginally associated $(\mathrm{p}=0.052$, OR $=0.70,95 \% \mathrm{CI}: 0.48-1.00)$ with less clearance compared to other HR-HPV genotypes.

\section{Discussion}

This study investigated the age-specific prevalence of overall HR-HPV, HPV16/18/45 and other HR-HPV in 25 to 65-year-old women without cervical precancer and cancer in a prospective study in rural China. It focused on the 
Table 2 Risk factors associated with overall HR-HPV infection at baseline by age group

\begin{tabular}{|c|c|c|c|}
\hline \multirow[t]{2}{*}{ Age-group } & \multirow[t]{2}{*}{ Risk factors* } & \multirow{2}{*}{$\begin{array}{l}\text { HPV } \\
\text { positive, n (\%) }\end{array}$} & \multirow{2}{*}{$\frac{\text { Multivariate }}{\text { OR }(95 \% \mathrm{Cl})}$} \\
\hline & & & \\
\hline \multirow[t]{15}{*}{$25-40(n=2587)$} & Household income (Yuan) ${ }^{\S}$ & & $p=0.023$ \\
\hline & $\leq 3000$ & $91(11.2)$ & 1.0 \\
\hline & $3001-5000$ & $79(10.1)$ & $0.96(0.69-1.34)$ \\
\hline & $\geq 5001$ & $125(12.7)$ & $1.41(1.04-1.92)$ \\
\hline & Marital status & & $p=0.007$ \\
\hline & Married & $289(11.3)$ & 1.0 \\
\hline & Others & $7(29.2)$ & $3.48(1.40-8.66)$ \\
\hline & Age at first menstruation period (years) ${ }^{\S}$ & & $p=0.027$ \\
\hline & $\leq 14$ & $140(10.5)$ & 1.0 \\
\hline & $15-16$ & $110(11.6)$ & $1.06(0.80-1.40)$ \\
\hline & $\geq 17$ & $46(15.3)$ & $1.65(1.14-2.40)$ \\
\hline & Age at first pregnancy (years) ${ }^{\S}$ & & $p=0.004$ \\
\hline & $\leq 20$ & $97(14.5)$ & 1.0 \\
\hline & $21-23$ & $136(11.0)$ & $0.77(0.57-1.03)$ \\
\hline & $\geq 24$ & $55(8.5)$ & $\mathbf{0 . 5 4}(0.38-0.78)$ \\
\hline \multirow[t]{4}{*}{$41-48(n=2530)$} & Age at first sexual intercourse (years) ${ }^{\S}$ & & $p<0.001$ \\
\hline & $\leq 19$ & $74(21.1)$ & 1.0 \\
\hline & $20-22$ & $173(10.9)$ & $\mathbf{0 . 4 9}(0.35-0.67)$ \\
\hline & $\geq 23$ & $66(11.2)$ & $\mathbf{0 . 5 2}(0.36-0.77)$ \\
\hline \multirow[t]{6}{*}{$49-65(n=2280)$} & No. of lifetime sex partners $\$$ & & $p=0.006$ \\
\hline & 1 & $306(15.0)$ & 1.0 \\
\hline & $\geq 2$ & $54(22.0)$ & $1.58(1.14-2.20)$ \\
\hline & Menopausal status ${ }^{\S}$ & & $p=0.008$ \\
\hline & No & $48(11.3)$ & 1.0 \\
\hline & Yes & $311(16.8)$ & $\mathbf{1 . 5 5}(1.12-2.15)$ \\
\hline
\end{tabular}

NOTE: *Only those risk factors of statistical significance in multivariate analysis which was adjusted for study sites, education level, oral contraceptive history, number of sex partners in the past 6 months, number of live births were shown. Age was categorized by tertiles at baseline. Bold type indicates statistical significance $(p<0.05) .{ }^{5}$ Missing values were excluded in the analysis. $\mathrm{HPV}=$ human papillomavirus; $\mathrm{OR}=$ odds ratio; $\mathrm{Cl}=$ confidence interval.

interpretation for the peak observed in older women. Moreover, we explored the risk factors of HPV incidence and clearance using one-year follow-up data.

The age-standardized prevalence by world population of HR-HPV tested by careHPV at baseline in our study was $14.2 \%$, which was comparable to other studies in mainland China [8-10], and other parts of Asia/Australia ( 15\%) [28]. However, it was lower than a pooled analysis from China (16.8\%) [13]. We reported a prevalence of $2.9 \%$ for HPV16 and/or 18 and/or 45 types, which was lower than other studies in China $[9,10]$. These differences are likely caused by different HPV DNA tests and different study populations, such as different geographic areas, different age groups, and different distributions of cervical lesions. We found that the prevalence as measured by careHPV was similar to the prevalence as measured by HC2 in our study $(\mathrm{p}=0.196)$, which suggested that the difference between the prevalence in this study and the recent pooled analysis [13] was primarily due to the differences among study populations.

Previous studies in China had observed a second peak of HPV prevalence in older women, although the peak age varied between studies [8-10,13]. In our study, HR-HPV prevalence peaked at 55-59 years, but lacked the "first peak" in younger women. It has been well acknowledged that cumulative risks of $40-50 \%$ of HPV acquisition happened within 2 to 3 years of sexual debut [29-32]. Since the average age at first sexual intercourse of our study participants was 21.2 years, the theoretical peak of HPV prevalence should appear in women aged 23-24 years. In addition, Chinese women were less likely to report their premarital and extramarital sexual histories. In that case, we hypothesize that the actually age of sexual initiation may be even younger. However, we only enrolled women aged over 25 years, therefore we have no chance to see the "first peak" as observed in other studies [13]. The one-year 


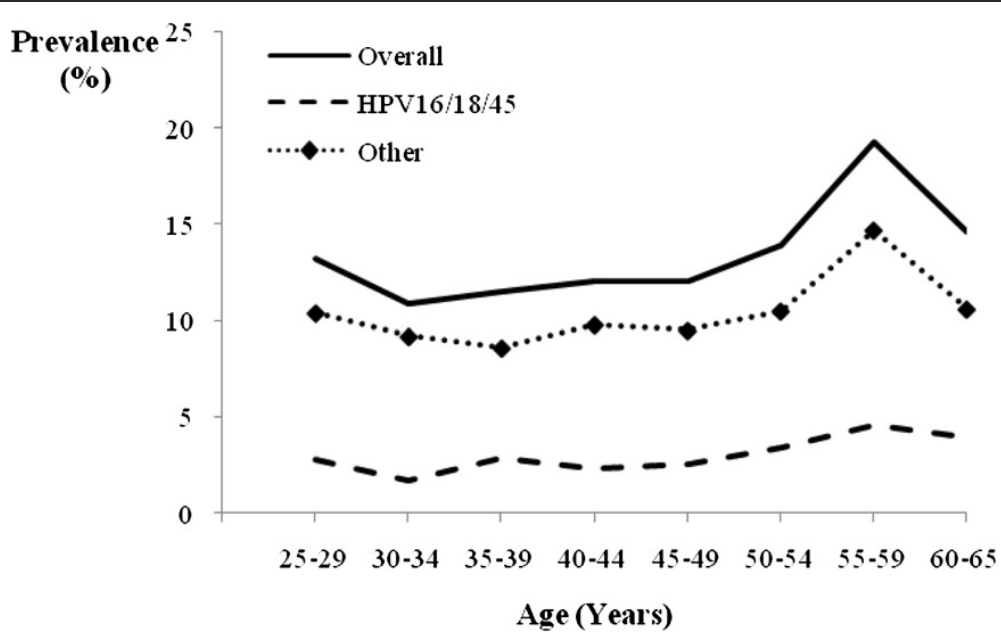

Figure 2 Age group-specific prevalence of any high-risk HPV, any HPV16, 18, and/or 45 (HPV16/18/45), and high-risk HPV other than HPV16/18/45 at baseline. Figure 2 Symbols: (bold line) Overall, (dash line) HPV16/18/45, (dot-dash line with solid diamond) Other.

prospective data demonstrated a larger number of infections that were cleared versus acquired, which indicated that HR-HPV prevalence should decrease with progressing of age, rather than a peak occurred in older women.

The probable explanations for this HR-HPV peak in older Chinese women could be a cohort effect that leads to increased lifetime exposures, increased HPV incidence and/ or increased viral persistence in older women [33] versus younger women. We considered each as described below.

\section{Cohort effects}

Before the one-child policy which had been strictly implemented in year 1979 [34], most women got married at an early age and gave a large number of births. Risk factor analysis in our study also found an earlier age at first sexual intercourse and a greater number of live births in 49 to 65-year-old women (data not shown), which may have led to a higher cumulative exposure to HR-HPV. And in some high-quality cancer registries in China, a declining trend in cervical cancer incidence from 1970's to 1990's has been observed [35]. This may partly reflect a higher HR-HPV burden in older generations (vs. younger generations according to a report from Sharma et al. [36], which found a positive association between age-standardized HPV prevalence and its square-root age-standardized cervical incidence).

However, one-year follow-up was not sufficient to provide a strong evidence to explain the cohort effect. Longterm follow-up studies with birth cohort analysis are needed to further clarify this effect. With recent changes in sexual norms, we anticipate an upturn in the annual incidence of cervical cancer in China unless widespread secondary prevention through screening, diagnosis, and treatment of precancerous lesions is implemented.

Table 3 Incidence, clearance and prevalence of overall HR-HPV infections at one-year follow-up by age

\begin{tabular}{|c|c|c|c|c|c|}
\hline Age group & Crude prevalence, $\mathrm{n} / \mathrm{N}(\%)$ & Adjusted prevalence, n/N (\%) & Adjusted incidence, $\mathrm{n} / \mathrm{N}$ (\%) & Clearance, n/N (\%) & $P^{a}$ \\
\hline $25-29$ & 15/102 (14.7) & 28/302 (9.3) & $21 / 269(7.8)$ & 26/33 (78.8) & 0.560 \\
\hline $30-34$ & $35 / 242(14.5)$ & $51 / 598(8.5)$ & $24 / 541(4.4)$ & $30 / 57(52.6)$ & 0.497 \\
\hline $35-39$ & $91 / 494(18.4)$ & $141 / 1275(11.1)$ & $82 / 1145(7.2)$ & $71 / 130(54.6)$ & 0.419 \\
\hline $40-44$ & 100/593 (16.9) & 163/1 $503(10.8)$ & 105/1 $339(7.8)$ & 106/164 (64.6) & 1.000 \\
\hline $45-49$ & 97/552 (17.6) & 125/1 $390(9.0)$ & $57 / 1235(4.6)$ & $87 / 155(56.1)$ & 0.015 \\
\hline $50-54$ & $91 / 345(26.4)$ & 108/877 (12.3) & 43/765 (5.6) & $47 / 112(42.0)$ & 0.752 \\
\hline $55-59$ & 100/315 (31.7) & $116 / 801(14.5)$ & $33 / 667(4.9)$ & $51 / 134(38.1)$ & 0.063 \\
\hline $60-65$ & $46 / 148(31.1)$ & $56 / 363(15.4)$ & $22 / 316(7.0)$ & $13 / 47(27.7)$ & 0.175 \\
\hline Total & $575 / 2791(20.6)$ & 788/7 $109(11.1)$ & $387 / 6277(6.2)$ & 431/832 (51.8) & 0.133 \\
\hline
\end{tabular}

NOTE: Since only a portion of baseline screen negative women were followed up at one-year, incidence was adjusted for the sampling fraction. It was calculated as follows: ((1/sampling fraction) * (Number of baseline screen negatives who tested careHPV-positive at follow-up) + (Number of baseline screen positives with careHPV-negative who tested careHPV-positive at follow-up)) / ((Number of baseline screen negatives) + (Number of baseline screen positives with careHPV-negative who were followed up)). The clearance was simply calculated by: (Number of cleared) / (Number of baseline careHPV-positive who were followed up). The adjusted prevalence at follow up was determined as: ((Number of baseline careHPV-positives who were not cleared) + (Number of incidence)) / Total population. Age groups were defined on the basis of age at baseline. a: the McNemar $x^{2}$ test is used to test for statistical differences in clearance and incidence; bold type indicates statistical significance $(p<0.05)$. 

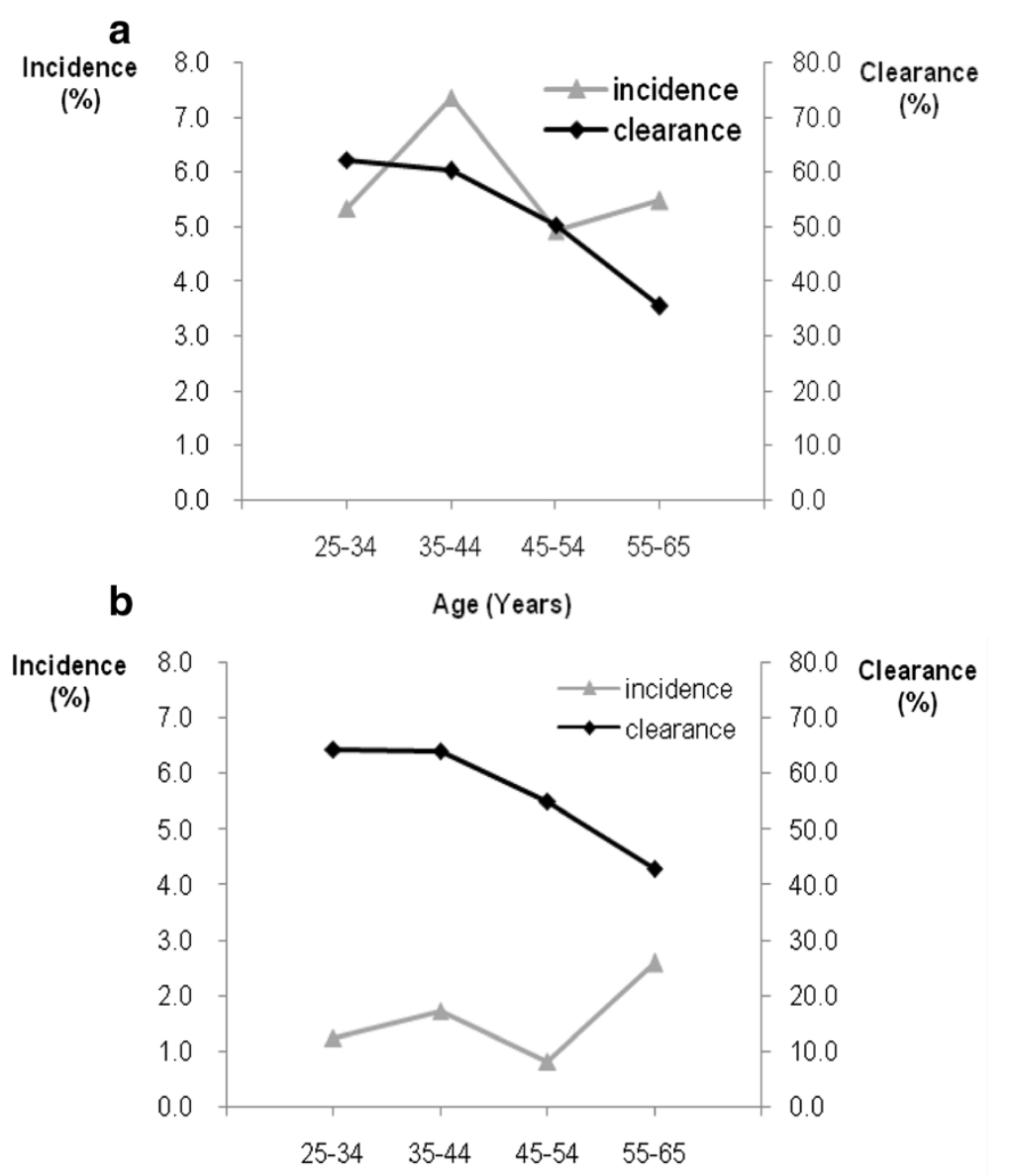

80.0 Clearance

70.0

(\%)

60.0

50.0

40.0

30.0

20.0

10.0

0.0

C

Age (Years)

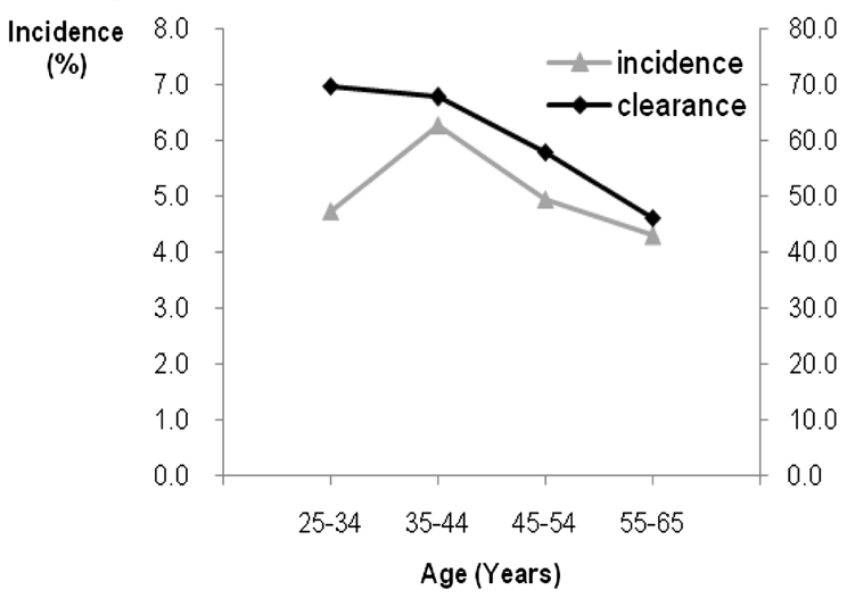

Figure 3 Incidence and clearance of HPV by age group. Incidence is adjusted for sampling fraction of baseline screen negatives. Age groups are defined on the basis of age at baseline. a. Incidence and clearance of overall HPV infection. b. Incidence and clearance of HPV16/18/45 infection. c. Incidence and clearance of other HPV infection. Figure 3 Symbols: (gray line with solid triangle) incidence, (black line with solid diamond) clearance.

\section{HPV incidence}

We expected to see a decreased trend in the incidence of HR-HPV infection in older women as reported in other studies [33,37], but only observed an independent relation. This unexpected higher incidence in older women may be caused by: 1) new HPV infections acquired by changes in sexual behaviors by either the women or their partners; 2) reactivation of latent HPV infection due to immune senescence $[38,39]$. No evidence supported the changes in sexual behaviors in older women although that does not rule 
Table 4 Risk factors associated with overall HR-HPV incidence and clearance

\begin{tabular}{|c|c|c|c|}
\hline Incidence/Clearance & Risk factors* & $\frac{\text { Univariate }}{\text { OR }(95 \% \mathrm{Cl})}$ & $\frac{\text { Multivariate }}{\text { OR }(95 \% \mathrm{Cl})^{\varepsilon}}$ \\
\hline \multirow[t]{4}{*}{ Incidence $(n=1959)$} & No. of sex partners in the past 6 months & $p=0.002$ & $p=0.001$ \\
\hline & 0 & 1.0 & 1.0 \\
\hline & 1 & $1.01(0.58-1.76)$ & $1.11(0.62-1.97)$ \\
\hline & 2 & $6.40(2.04-20.05)$ & $7.80(2.46-24.75)$ \\
\hline \multirow[t]{34}{*}{ Clearance $(n=832)$} & Age (years) & $p<0.001$ & $p<0.001$ \\
\hline & $25-29$ & 1.0 & 1.0 \\
\hline & $30-34$ & $\mathbf{0 . 3 0}(0.11-0.80)$ & $\mathbf{0 . 2 8}(0.10-0.78)$ \\
\hline & $35-39$ & $\mathbf{0 . 3 2}(0.13-0.80)$ & $\mathbf{0 . 3 6}(0.14-0.91)$ \\
\hline & $40-44$ & $0.49(0.20-1.20)$ & $0.48(0.19-1.21)$ \\
\hline & $45-49$ & $0.34(0.14-0.84)$ & $0.35(0.14-0.89)$ \\
\hline & $50-54$ & $\mathbf{0 . 2 0}(0.08-0.49)$ & $\mathbf{0 . 1 9}(0.07-0.48)$ \\
\hline & $55-59$ & $\mathbf{0 . 1 7}(0.07-0.41)$ & $\mathbf{0 . 1 5}(0.06-0.38)$ \\
\hline & $60-65$ & $\mathbf{0 . 1 0}(0.04-0.30)$ & $0.11(0.04-0.33)$ \\
\hline & Education level (years) & $p=0.001$ & $p=0.204$ \\
\hline & $\leq 6$ & 1.0 & \\
\hline & $7-12$ & $1.61(1.22-2.13)$ & \\
\hline & $\geq 13$ & $3.29(1.03-10.51)$ & \\
\hline & Age at first sexual intercourse (years) & $p=0.037$ & $p=0.496$ \\
\hline & $\leq 19$ & 1.0 & \\
\hline & $20-22$ & $1.46(1.05-2.04)$ & \\
\hline & $\geq 23$ & $1.06(0.72-1.56)$ & \\
\hline & No. of sex partners in the past 6 months & $p=0.014$ & $p=0.066$ \\
\hline & 0 & 1.0 & \\
\hline & 1 & $1.68(1.08-2.58)$ & \\
\hline & 2 & $0.60(0.20-1.84)$ & \\
\hline & Menopausal status ${ }^{\S}$ & $p<0.001$ & $p=0.433$ \\
\hline & No & 1.0 & \\
\hline & Yes & $\mathbf{0 . 4 1}(0.31-0.55)$ & \\
\hline & No. of live births ${ }^{\S}$ & $p<0.001$ & $p=0.695$ \\
\hline & $0-2$ & 1.0 & \\
\hline & $\geq 3$ & $\mathbf{0 . 5 7}(0.42-0.76)$ & \\
\hline & Signal strength (RLU/CO) & $p<0.001$ & $p<0.001$ \\
\hline & $1.00-9.99$ & 1.0 & 1.0 \\
\hline & 10.00-99.99 & $\mathbf{0 . 2 7}(0.20-0.38)$ & $\mathbf{0 . 2 8}(0.20-0.40)$ \\
\hline & $\geq 100.00$ & $\mathbf{0 . 4 3}(0.29-0.62)$ & $\mathbf{0 . 4 0}(0.27-0.59)$ \\
\hline & HPV16/18/45 & $p<0.001$ & $p=0.052$ \\
\hline & Negative & 1.0 & 1.0 \\
\hline & Positive & $\mathbf{0 . 5 6}(0.40-0.78)$ & $0.70(0.48-1.00)$ \\
\hline
\end{tabular}

NOTE: *Risk factors were defined on the basis of risk factors at baseline. ${ }^{\varepsilon}$ Multivariate logistic model was adjusted for study sites, household income, marital status and oral contraceptive for incidence and clearance. Furthermore, for incidence, VIA and HC2 results at baseline were also adjusted in the multivariate analysis. HPV16/18/45 was put into the model for marginally association. In the multivariate analysis, OR was given only if statistical significant. ${ }^{\S}$ Missing values were excluded in the analysis. Bold type indicated statistical significant $(p<0.05)$. $\mathrm{HPV}=$ human papillomavirus; $\mathrm{OR}=$ odds ratio; $\mathrm{Cl}=\mathrm{confidence}$ interval. 
out that their male partners were having new partners and transmitting HPV to them. However, we noted differences in risk factors associated with HPV infection between women aged 25-40 years and women aged 49-65 years. Number of lifetime sex partners, which may be proxy for cumulative exposure impact [40], was only found to be associated with HPV infection in older women. Greater early exposure to HR-HPV infection and weakened immune response after menopause [41] that led to the reemergence of latent HPV infections could cause a second HPV peak in older women. Gravitt et al. [39] found that there was a second peak around 50-54 years in women with five or more sex partners but not in those with less than four sex partners. Their findings may support that the second peak could be seen in a more generalized population with a relatively higher cumulative probability of HPV infection.

\section{HPV persistence}

Another explanation, a greater HPV persistence in older women, was strongly supported by our data (see Additional file 1: Figure S1). We found an obvious trend of decreasing clearance or increasing persistence of HPV with increasing age. The mechanisms could be: 1) decreased ability to clear recent infections with age-related immune senescence; 2) predominance of long-duration prevalent infections in older women from earlier exposures [33].

Thus, we found that the cause of the second peak in HPV prevalence may be multi-factorial. Despite of the low number of sex partners, the rural Chinese women were usually married at an early age and gave a large number of births. The lifestyles and economic status of the older rural Chinese women were also much different from other populations and younger generations. Their poor nutrition and sanitary condition may cause a poor immune function, which may in turn result in a reduced ability to clear $\mathrm{HPV}$ infections and to control/prevent the re-emergence of latent HPV infections.

Our findings agreed with the previous study conducted in Guanacaste, Costa Rica, which also found that HPV infections tended to clear more often than acquire, and persistence increased with age [33]. However, unlike the study in Guanacaste, Costa Rica, we did not observe newly detected infections declining with age.

\section{Risk factors}

We also explored the risk factors for HPV prevalence, incidence and clearance using both univariate and multivariate models. Most of our results were similar to the others $[42,43]$, however, we failed to find the association between the number of sex partners in the past 6 months and HPV prevalence in the multivariate model. This may be explained by the fact that most of the participants reported to have no or one sex partners in the past 6 months. To our knowledge, this may not be entirely accurate as some women may be reluctant to report their actual behaviors.

\section{Impact for cervical cancer screening}

The incidence of HPV16,18, and/or 45 was higher and the clearance was lower in 55 to 65-year-old women, they are of the greatest risk of persisting HPV16/18/45 infections, which cause $75 \%$ of cervical cancer worldwide [44]. Women aged 55-65 years may be at the highest risk of progression to cervical precancer or cancer. However, the first large-scaled cervical cancer screening program in rural China launched by Chinese government from 2009 to 2011 using VIA or Pap smear does not cover women older than 60 years [45]. If further studies show these infections representing significant cancer risk in older women, expanding screening to older ages should be considered in the future nationwide program in China.

\section{Limitations}

This analysis has some limitations. First of all, convenience sampling was used in recruiting, the participants may not be perfectly representative. Second, we only followed up $\sim 20 \%$ of the screen negatives, even with adjustment, the estimated incidence and prevalence at follow-up might differ somewhat from the actual values. Whereas, we conducted a random sampling to get the list of screen-negative women, so the bias was minimized. Third, we did not test for the specific HPV type, so that we could not get the precise status of HPV incidence or clearance. Given that multiple infections typically represent $20-30 \%$ of all HR-HPV infections and are often more common in younger women [46], we likely underestimated both one-year clearance and incidence. However, we granted the same patterns of clearance and incidence for HPV16/18/45 infections as the overall HR-HPV infections, which may reflect a relatively low percentage of women with co-infections of the three types. We only use a pooled DNA test for 14 certain and probable HR-HPV types to generally describe the age-group specific patterns of HR-HPV, which is relevant to cervical cancer screening and the risk factors associated.

We used clinical tests for HPV, which may have missed some lower viral load HPV infections that are not strongly associated with CIN2+. To address this issue, we conducted an additional analysis by defining HPV positive as either care HPV or $\mathrm{HC} 2$ tested positive to increase the analytic sensitivity. And we observed similar results.

Another notable limitation was the short follow-up time. As a consequence, some infections persisted for a year but would have later cleared, while some infections that appeared to clear were testing errors and would have tested positive subsequently. However, based on the results from a meta-analysis which found the median 
duration of HR-HPV detection was 10.9 months in those HPV-positive women with normal cytology [47], we believe that measuring the pattern over a year was a good surrogate for the longer-term persistence. Previous studies have shown that one-year HPV persistence can strongly predict longer-term persistence [17] and CIN2+ [47-49].

\section{Conclusions}

Our study observed an increase of HR-HPV prevalence in older women in rural China. The probable explanations could be: 1) cohort effect; 2) higher than expected incidence; and/or 3) poorer clearance/greater persistence of HR-HPV at older ages. Long-term prospective studies with frequent follow-up intervals by HPV genotyping are needed to verify the conclusions from this study.

\section{Additional file}

Additional file 1: Figure S1. Age group-specific, one-year persistence of any high-risk HPV, any HPV16, 18, and/or 45 (HPV16/18/45), and high-risk HPV other than HPV16/18/45. Additional file 1: Figure S1 Symbols: (bold line) Overall, (dash line) HPV16/18/45, (the dot-dash line with solid diamond) Other.

\section{Competing interests}

PEC has received commercial HPV tests for research at a reduced or no cost from Roche, QIAGEN, Norchip, and $\mathrm{mtm}$. He is a paid consultant for BD, GE Healthcare, and Cepheid, and has received a speaker's honorarium from Roche. He is a paid consultant for Immunexpress on sepsis diagnostics. He is compensated as a member of a Merck Data and Safety Monitoring Board for HPV vaccines. JJ was the director of the study and received all the tests used in the study as a donation from the manufacturing companies (QIAGEN and Arbor Vita Corporation). All other authors have no competing interests.

\section{Authors' contributions}

PEC, JJ and YLQ contributed to conception and design of the study. All authors were involved in the study implementation. LNK, FHZ, JJ, FC, JL, WC, XZ assisted in the data collection; LNK, JJ, PB, JL contributed to the data management. PEC, LNK designed the analysis; all authors were involved in data analysis and interpretation. LNK, PEC, and YLQ drafted manuscript. All authors read and approved the final manuscript.

\section{Acknowledgements}

We thank all the study staffs from CICAMS, PATH, Yangcheng MCH, Xinmi $\mathrm{MCH}$ and Tonggu MCH, for their hard work and support of this project. We also thank all the participants in this study.

\section{Sources of support}

The Screening Technologies to Advance Rapid Testing for Cervical Cancer Prevention-Utility and Program Planning (START-UP) Projects funded in whole by a grant from the Bill \& Melinda Gates Foundation. The views expressed herein are solely those of the authors and do not necessarily reflect the views of the foundation.

\section{Author details}

${ }^{1}$ Cancer Institute and Hospital, Chinese Academy of Medical Sciences and Peking Union Medical College, 17 Panjiayuan Lane, Beijing 100021, China. ${ }^{2}$ Global Cancer Initiative, 100 Radcliff Drive, Chestertown, MD 21620, USA. ${ }^{3}$ PATH, 2201 Westlake Avenue, Suite 200, Seattle, WA 98121, USA.

Received: 9 November 2013 Accepted: 12 February 2014 Published: 21 February 2014

\section{References}

1. Schiffman M, Castle PE, Jeronimo J, Rodriguez AC, Wacholder S: Human papillomavirus and cervical cancer. Lancet 2007, 370:890-907.

2. Clifford GM, Gallus S, Herrero R, Muñoz N, Snijders PJ, Vaccarella S, Anh PT, Ferreccio C, Hieu NT, Matos E, et al: Worldwide distribution of human papillomavirus types in cytologically normal women in the International Agency for Research on Cancer HPV prevalence surveys: a pooled analysis. Lancet 2005, 366:991-998.

3. Franceschi S, Herrero R, Clifford GM, Snijders PJ, Arslan A, Anh PT, Bosch FX,

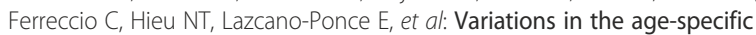
curves of human papillomavirus prevalence in women worldwide. Int J Cancer 2006, 119:2677-2684.

4. Ferreccio C, Prado RB, Luzoro AV, Ampuero SL, Snijders PJ, Meijer CJ, Vaccarella SV, Jara AT, Puschel KI, Robles SC, et al: Population-based prevalence and age distribution of human papillomavirus among women in Santiago, Chile. Cancer Epidemiol Biomarkers Prev 2004, 13:2271-2276.

5. Herrero R, Castle PE, Schiffman M, Bratti MC, Hildesheim A, Morales J, Alfaro M, Sherman ME, Wacholder S, Chen S, et al: Epidemiologic profile of type-specific human papillomavirus infection and cervical neoplasia in Guanacaste, Costa Rica. J Infect Dis 2005, 191:1796-1807.

6. Peto J, Gilham C, Deacon J, Taylor C, Evans C, Binns W, Haywood M, Elanko $\mathrm{N}$, Coleman D, Yule R, et al: Cervical HPV infection and neoplasia in a large population-based prospective study: the Manchester cohort. Br J Cancer 2004, 91:942-953.

7. Kjaer SK, Breugelmans G, Munk C, Junge J, Watson M, Iftner T: Populationbased prevalence, type- and age-specific distribution of HPV in women before introduction of an HPV-vaccination program in Denmark./Emphasis> Int J Cancer 2008, 123:1864-1870.

8. Dai M, Bao YP, Li N, Clifford GM, Vaccarella S, Snijders PJ, Huang RD, Sun LX, Meijer CJ, Qiao YL, et al: Human papillomavirus infection in Shanxi Province, People's Republic of China: a population-based study. Br J Cancer 2006, 95:96-101.

9. Li LK, Dai M, Clifford GM, Yao WQ, Arslan A, Li N, Shi JF, Snijders PJ, Meijer CJ, Qiao YL, et al: Human papillomavirus infection in Shenyang City, People's Republic of China: a population-based study. Br J Cancer 2006, 95:1593-1597.

10. Wu RF, Dai M, Qiao YL, Clifford GM, Liu ZH, Arslan A, Li N, Shi JF, Snijders PJ, Meijer CJ, et al: Human papillomavirus infection in women in Shenzhen City, People's Republic of China, a population typical of recent Chinese urbanisation. Int J Cancer 2007, 121:1306-1311.

11. Liu SS, Chan KY, Leung RC, Chan KK, Tam KF, Luk MH, Lo SS, Fong DY, Cheung AN, Lin ZQ, et al: Prevalence and risk factors of Human Papillomavirus (HPV) infection in southern Chinese women - a population-based study. PLoS One 2011, 6:e19244.

12. Yu XW, Zhang XW, Wang L, Li F, Xu J: Status of human papillomavirus infection in the rural female population in Northwestern China: an observational study. J Low Genit Tract Dis 2013, 17:17-22.

13. Zhao FH, Lewkowitz AK, Hu SY, Chen F, Li LY, Zhang QM, Wu RF, Li CQ, Wei $L H, X u A D$, et al: Prevalence of human papillomavirus and cervical intraepithelial neoplasia in China: a pooled analysis of 17 populationbased studies. Int J Cancer 2012, 131:2929-2938.

14. Walboomers JM, Jacobs MV, Manos MM, Bosch FX, Kummer JA, Shah KV Snijders PJ, Peto J, Meijer CJ, Muñoz N: Human papillomavirus is a necessary cause of invasive cervical cancer worldwide. J Pathol 1999, 189:12-19.

15. Boulet GA, Horvath CA, Berghmans S, Bogers J: Human papillomavirus in cervical cancer screening: important role as biomarker. Cancer Epidemiol Biomarkers Prev 2008, 17:810-817.

16. Bosch FX, Lorincz A, Muñoz N, Meijer CJ, Shah KV: The causal relation between human papillomavirus and cervical cancer. J Clin Pathol 2002, 55:244-265.

17. Plummer M, Schiffman M, Castle PE, Maucort-Boulch D, Wheeler CM, ALTS Group: A 2-year prospective study of human papillomavirus persistence among women with a cytological diagnosis of atypical squamous cells of undetermined significance or low-grade squamous intraepithelial lesion. J Infect Dis 2007, 195:1582-1589.

18. Koshiol J, Lindsay L, Pimenta JM, Poole C, Jenkins D, Smith JS: Persistent human papillomavirus infection and cervical neoplasia: a systematic review and meta-analysis. Am J Epidemiol 2008, 168:123-137.

19. Saslow D, Solomon D, Lawson HW, Killackey M, Kulasingam SL, Cain J, Garcia FA, Moriarty AT, Waxman AG, Wilbur DC, et al: American Cancer 
Society, American Society for Colposcopy and Cervical Pathology, and American Society for Clinical Pathology screening guidelines for the prevention and early detection of cervical cancer. Am J Clin Pathol 2012, 137:516-542.

20. Gage JC, Ajenifuja KO, Wentzensen N, Adepiti AC, Stoler M, Eder PS, Bell L, Shrestha N, Eklund C, Reilly M, et al: Effectiveness of a simple rapid human papillomavirus DNA test in rural Nigeria. Int J Cancer 2012, 131:2903-2909.

21. Qiao YL, Sellors JW, Eder PS, Bao YP, Lim JM, Zhao FH, Weigl B, Zhang WH, Peck RB, Li L, et al: A new HPV-DNA test for cervical-cancer screening in developing regions: a cross-sectional study of clinical accuracy in rural China. Lancet Oncol 2008, 9:929-936.

22. Zhao FH, Jeronimo J, Qiao YL, Schweizer J, Chen W, Valdez M, Lu P, Zhang $X$, Kang LN, Bansil P, et al: An evaluation of novel, lower-cost molecular screening tests for human papillomavirus in rural China. Cancer Prev Res (Phila) 2013, 6:938-948.

23. Pretorius RG, Zhang WH, Belinson JL, Huang MN, Wu LY, Zhang X, Qiao YL, et al: Colposcopy directed biopsy, random cervical biopsy, and endocervical curettage in the diagnosis of cervical intraepithelial neoplasia II or worse. Am J Obstet Gynecol 2004, 191:430-434.

24. Gravitt PE, Burk RD, Lorincz A, Herrero R, Hildesheim A, Sherman ME, Bratti $M C$, Rodriguez AC, Helzlsouer KJ, Schiffman M: A comparison between real-time polymerase chain reaction and hybrid capture 2 for human papillomavirus DNA quantitation. Cancer Epidemiol biomarkers Prev 2003, 12:477-484

25. Ahmad OB, Boschi-Pinto C, Lopez AD, Murray CJ, Lozano R, Inoue M: Age standardization of rates: a new WHO standard. Series: No . 31. Geneva: World Health Organization Press; 2001:10 [www.who.int/healthinfo/paper31.pdf].

26. Moodley JR, Constant D, Hoffman M, Salimo A, Allan B, Rybicki E, Hitzeroth I, Williamson $\mathrm{AL}$, et al: Human papillomavirus prevalence, viral load and pre-cancerous lesions of the cervix in women initiating highly active antiretroviral therapy in South Africa: a cross-sectional study. BMC Cancer 2009, 9:275.

27. Safaeian M, Herrero R, Hildesheim A, Quint W, Freer E, Van Doorn $\sqcup$, Porras C, Silva S, González P, Bratti MC, et al: Comparison of the SPF10-LiPA system to the hybrid capture 2 assay for detection of carcinogenic human papillomavirus genotypes among 5,683 young women in Guanacaste, Costa Rica. J Clin Microbiol 2007, 45:1447-1454.

28. Smith JS, Melendy A, Rana RK, Pimenta JM: Age-specific prevalence of infection with human papillomavirus in females: a global review. J Adolesc Health 2008, 43(4 Suppl):S5-S25.

29. Collins S, Mazloomzadeh S, Winter H, Blomfield P, Bailey A, Young LS, Woodman CB: High incidence of cervical human papillomavirus infection in women during their first sexual relationship. BJOG 2002, 109:96-98.

30. Winer RL, Lee SK, Hughes JP, Adam DE, Kiviat NB, Koutsky LA: Genital human papillomavirus infection: incidence and risk factors in a cohort of female university students. Am J Epidemiol 2003, 157:218-226.

31. Rodriguez AC, Burk R, Herrero R, Hildesheim A, Bratti C, Sherman ME, Solomon D, Guillen D, Alfaro M, Viscidi R, et al: The natural history of human papillomavirus infection and cervical intraepithelial neoplasia among young women in the Guanacaste cohort shortly after initiation of sexual life. Sex Transm Dis 2007, 34:494-502.

32. Moscicki AB: Management of adolescents who have abnormal cytology and histology. Obstet Gynecol Clin North Am 2008, 35:633-643.

33. Castle PE, Schiffman M, Herrero R, Hildesheim A, Rodriguez AC, Bratti MC, Sherman ME, Wacholder S, Tarone R, Burk RD: A prospective study of age trends in cervical human papillomavirus acquisition and persistence in Guanacaste, Costa Rica. J Infect Dis 2005, 191:1808-1816.

34. Wang C: History of the Chinese family planning progrom: 1970-2010. Contraception 2012, 85:563-569.

35. Wei $\mathrm{K}$, Wang $\mathrm{Y}$, Liang Z: An analysis of incidence with cervical cancer in $1970 \sim 2007$ in Zhongshan city, Guangdong province. China Cancer 2012, 21:495-497. in Chinese.

36. Sharma M, Bruni L, Diaz M, Castellsagué X, de Sanjosé S, Bosch FX, Kim JJ: Using HPV prevalence to predict cervical cancer incidence. Int I Cancer 2013, 132:1895-1900.

37. Goodman MT, Shvetsov YB, McDuffie K, Wilkens LR, Zhu X, Thompson PJ, Ning L, Killeen J, Kamemoto L, Hernandez BY: Prevalence, acquisition, and clearance of cervical human papillomavirus infection among women with normal cytology: Hawaii human papillomavirus cohort study. Cancer Res 2008, 68:8813-8824.
38. Gravitt PE, Rositch AF, Silver MI, Marks MA, Chang K, Burke AE, Viscidi RP: A cohort effect of the sexual revolution may be masking an increase in human papillomavirus detection at menopause in the United States. $J$ Infect Dis 2012, 207:272-280.

39. Bosch FX, Burchell AN, Schiffman M, Giuliano AR, de Sanjose S, Bruni L, Tortolero-Luna G, Kjaer SK, Muñoz N: Epidemiology and natural history of human papillomavirus infections and type-specific implications in cervical neoplasia. Vaccine 2008, 26(Suppl 1):K1-K16.

40. Strickler HD, Kirk GD, Figueroa JP, Ward E, Braithwaite AR, Escoffery C, Drummond J, Goebel B, Waters D, McClimens R, et al: HPV 16 antibody prevalence in Jamaica and the United States reflects differences in cervical cancer rates. Int J Cancer 1999, 80:339-344.

41. González P, Hildesheim A, Rodríguez AC, Schiffman M, Porras C, Wacholder $S$, Piñeres AG, Pinto LA, Burk RD, Herrero R: Behavioral/lifestyle and immunologic factors associated with HPV infection among women older than 45 years. Cancer Epidemiol Biomarkers Prev 2010, 19:3044-3054.

42. Lai CH, Chao A, Chang CJ, Chao FY, Huang HJ, Hsueh S, Lin CT, Cheng HH, Huang CC, Yang JE, et al: Host and viral factors in relation to clearance of human papillomavirus infection: a cohort study in Taiwan. Int J Cancer 2008, 123:1685-1692.

43. Sellors JW, Karwalajtys TL, Kaczorowski J, Mahony JB, Lytwyn A, Chong S, Sparrow J, Lorincz A, et al: Incidence, clearance and predictors of human papillomavirus infection in women. CMAJ 2003, 168:421-425.

44. de Sanjose S, Quint WG, Alemany L, Geraets DT, Klaustermeier JE, Lloveras B, Tous S, Felix A, Bravo LE, Shin HR, et al: Human papillomavirus genotype attribution in invasive cervical cancer: a retrospective cross-sectional worldwide study. Lancet Oncol 2010, 11:1048-1056.

45. The Lancet: Women's health in rural China. Lancet 2009, 374:358.

46. Méndez F, Muñoz N, Posso H, Molano M, Moreno V, van den Brule AJ, Ronderos M, Meijer C, Muñoz A, et al: Cervical coinfection with Human Papillomavirus (HPV) types and possible implications for the prevention of cervical cancer by HPV vaccines. J Infect Dis 2005, 192:1158-1165.

47. Rositch AF, Koshiol J, Hudgens MG, Razzaghi H, Backes DM, Pimenta JM, Franco EL, Poole C, Smith JS: Patterns of persistent genital human papillomavirus infection among women worldwide: a literature review and meta-analysis. Int J Cancer 2013, 133:1271-1285.

48. Rodríguez AC, Schiffman M, Herrero R, Wacholder S, Hildesheim A, Castle $P E$, Solomon D, Burk R: Rapid clearance of human papillomavirus and implications for clinical focus on persistent infections. J Nat/ Cancer Inst 2008, 100:513-517.

49. Castle PE, Rodriguez AC, Burk RD, Herrero R, Wacholder S, Alfaro M, Morales J, Guillen D, Sherman ME, Solomon D, et al: Short term persistence of human papillomavirus and risk of cervical precancer and cancer: population based cohort study. BMJ 2009, 339:b2569.

\section{doi:10.1186/1471-2334-14-96}

Cite this article as: Kang et al: A prospective study of age trends of high-risk human papillomavirus infection in rural China. BMC Infectious Diseases 2014 14:96.

\section{Submit your next manuscript to BioMed Central and take full advantage of:}

- Convenient online submission

- Thorough peer review

- No space constraints or color figure charges

- Immediate publication on acceptance

- Inclusion in PubMed, CAS, Scopus and Google Scholar

- Research which is freely available for redistribution 